\title{
USE OF A MULTISPECTRAL UAV PHOTOGRAMMETRY FOR DETECTION AND TRACKING OF FOREST DISTURBANCE DYNAMICS
}

\author{
R. Minařík ${ }^{\mathrm{a}}$, J. Langhammer ${ }^{\mathrm{a}, *}$ \\ ${ }^{a}$ Dept. of Physical Geography and Geoecology, Faculty of Science, Charles University in Prague, Albertov 6, Prague 2, 128 43, \\ Czech Republic - (robert.minarik, jakub.langhammer)@natur.cuni.cz
}

Commission VIII, WG VIII/7

KEY WORDS: UAV, Photogrammetry, Multispectral Sensor, Forest Disturbance, Vegetation Indices, Change Detection

\begin{abstract}
:
This study presents a new methodological approach for assessment of spatial and qualitative aspects of forest disturbance based on the use of multispectral imaging camera with the UAV photogrammetry. We have used the miniaturized multispectral sensor Tetracam Micro Multiple Camera Array ( $\mu$-MCA) Snap 6 with the multirotor imaging platform to get multispectral imagery with high spatial resolution. The study area is located in the Sumava Mountains, Central Europe, heavily affected by windstorms, followed by extensive and repeated bark beetle (Ips typographus [L.]) outbreaks in the past 20 years. After two decades, there is apparent continuous spread of forest disturbance as well as rapid regeneration of forest vegetation, related with changes in species and their diversity. For testing of suggested methodology, we have launched imaging campaign in experimental site under various stages of forest disturbance and regeneration. The imagery of high spatial and spectral resolution enabled to analyse the inner structure and dynamics of the processes. The most informative bands for tree stress detection caused by bark beetle infestation are band $2(650 \mathrm{~nm})$ and band $3(700 \mathrm{~nm})$, followed by band $4(800 \mathrm{~nm})$ from the, red-edge and NIR part of the spectrum. We have identified only three indices, which seems to be able to correctly detect different forest disturbance categories in the complex conditions of mixture of categories. These are Normalized Difference Vegetation Index (NDVI), Simple 800/650 Ratio Pigment specific simple ratio B1 and Red-edge Index.
\end{abstract}

\section{INTRODUCTION}

Disturbance is the key control of the dynamics of forest ecosystems across various environments (Frelich, 2002). It has enormous effects on related landscape processes ranging from the changes in microclimate and runoff dynamics (Langhammer et al., 2015) to land cover changes and soil erosion (Borrelli et al., 2016). Various factors cause the disturbance such as air pollution, storms, unregulated harvesting and pest insect outbreak), but the most significant impacts that may affect the dynamics of mountain forests in Central and Western Europe are considered by windstorms and bark beetle outbreaks (Kulakowski and Bebi, 2004). In Central Europe, especially the Sumava Mountains has undergone a significant forest disturbance in the past two decades as a result of repeated windstorms and bark beetle infestation (Ips typographus [L.]) (Hais et al., 2009). Simultaneously, this area is experiencing significant increases in observed air temperatures (Langhammer et. al, 2015), which might cause a raise in the frequency of extreme weather events and promote forest diseases (Lindner et al., 2010).

Damage monitoring and risk assessment of bark beetles have traditionally been based on laborious and time-consuming field sampling methods, focusing on symptoms on the trunk and foliage (Göthlin et al., 2000; Lausch et al. 2013). In general, an invasion by bark beetle causes visible crown symptoms, i.e., discoloration and defoliation, before succumbing from the infestation (Näsi et al., 2015). The needles of Norway spruce first turn yellow (yellow attack), then to reddish brown (red attack), and finally grey (tree mortality) (Ortiz et al., 2013). Consequently, remote sensing technologies are widely applied for non-invasive mapping of forest disturbance by pest insects. Multi-temporal medium or low resolution satellite datasets like Landsat (TM/ETM+) and SPOT (Hais et al., 2009; Latifi et al., 2014), Colour-Infrared (CIR) images captured by manned aircraft (Heurich et al., 2010), TerraSAR-X and RapidEye data (Ortiz et al., 2013; Adamczyk and Osberger, 2015), or airborne pushbroom imagining radiometer (Campbell et al., 2004) have been used for monitoring of disturbances by bark beetle infestation. However, conventional remote sensing (RS) methods are not always appropriate for monitoring forest disturbance dynamics particularly in the case of rapid calamity mapping of small privately owned forest stands due to a high operating cost or limited spatial and temporal image data (Chambers et. al, 2007). These applications require low-cost but high-resolution RS data and acquisition on demand. By addressing the limitations of conventional remote sensing approaches in forestry, Unmanned Aerial Vehicle (UAV) equipped with a multi or hyperspectral camera may provide accurate means of monitoring pest infestation at the stand and even species level (Lehmann et al., 2015).

UAV has been widely applied for RS of the environment and vegetation areas. Compared to satellite-based RS applications, UAV-based applications have a much better resolution and greater flexibility in selecting suitable payloads and appropriate spatiotemporal resolution (Zhang and Kovacs, 2012). When comparing UAV-based applications with full-scale manned aircraft RS, UAV has lower operating costs and flight altitude

* Corresponding author 
closer to treetops providing very detailed insight into forest dynamics (Näsi et al., 2015). The current review of UAV flight experiments applied to the RS of vegetated areas including taxonomy is presented in Salamí et al. (2014). Approximately $40 \mathrm{UAV}$ experiments are introduced in the review, but only six studies are centred on forest mapping. In environment monitoring, Laliberte et al. (2011) employed multispectral sensor carried by UAV for rangeland vegetation classification. Turner et al. (2014) investigated the physiological state of Antarctic Moss ecosystems using UAV equipped with tree different (visible, multispectral and thermal) sensors.

Rapidly increasing pest-induced forest disturbances are a threat to forest health, therefore, accurate and cost-efficient detection of stand and tree conditions for timely forest management are needed, but studies employing UAV in forest health monitoring are rare and there is an open space for new projects (Näsi et. al., 2015).

Lehmann et al. (2015) were one of the first researches that used UAV for detection of pest infestation level in forest ecosystem Authors used multispectral imagery and object-based image analysis to detect an infestation in oak stands. The UAV was equipped with a calibrated consumer-grade digital camera with removed hot mirror filter to obtain modified colour infrared (CIR) images. Näsi et al. (2015) introduced the first study which investigated bark beetle damage at tree-level by means of UAV photogrammetry and hyperspectral imaging. In agriculture, tree health monitoring with multispectral, hyperspectral or thermal UAV- based data have been studied, e.g. vineyard (Turner et al., 2011) and peach orchard (Berni et al., 2009).

The aim of the study is to introduce a new methodological approach for assessment of spatial and qualitative aspects of forest disturbance at high spatial and spectral resolution. This study combines the use of multispectral imaging sensor Tetracam $\mu$-MCA Snap 6 with the UAV Mikrokopter OctoXL platform. Using the photogrammetric tools there was derived seamless high-resolution multispectral imagery covering the study area. Based on the acquired seamless dataset there we have performed a qualitative analysis of the different categories of the disturbance and regeneration of Norway spruce forest.

\section{MATERIAL AND METHODS}

\subsection{Study Site}

The study site is situated in the Sumava mountains at the border between the Czech Republic and Germany (Figure 1a), formed by an elevated montane plain with moderate hillslopes. The Norway spruce (Picea abies) monoculture is the dominant tree species in the regions. After the windstorms in the Bavarian side of mountains in mid of 1980's there occurred a massive bark beetle (Ips typographus [L.]) infestation, which resulted in extensive forest disturbance and decay. The infestation was accelerated after the windstorms in 2007 and 2008 and in terms of its extent and intensity is significant at European scale (Borrelli et al., 2016). While the area is protected as a National Park, the forest was left to the natural processes of forest disturbance, decay, and regeneration without human intervention. In result, the former forest monoculture is recently featuring mixed structure of the old forest, disturbed standing trees, decayed tree trunks and spots of the newly regenerating young forest.
We have selected the study site at headwaters of Hamerský brook near Kvilda village, with high recent dynamics of forest cover changes. In the study site, sized $150 \times 100$ meters (Figure 1b), where we have identified the research plot with an appropriate mosaic of forest disturbance categories (Figure 1c). Based on the field observation, there were chosen representative samples of the five classes (infested trees, healthy trees, dead trees, forest restoration, grass) to investigate their spectral response. For a selection of the test plot, we have aimed for particular samples, featuring (i) high level of heterogeneity in terms of forest disturbance categories and (ii) high level of homogeneity inside the selected category.

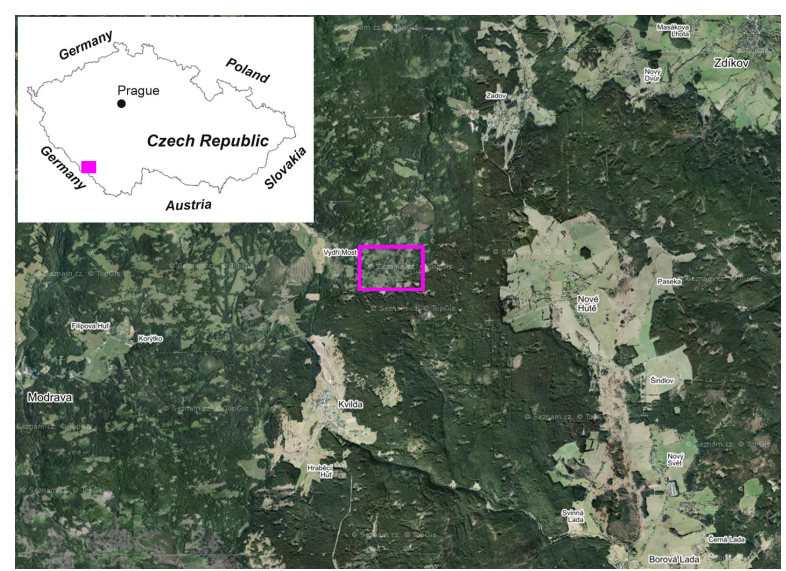

a)

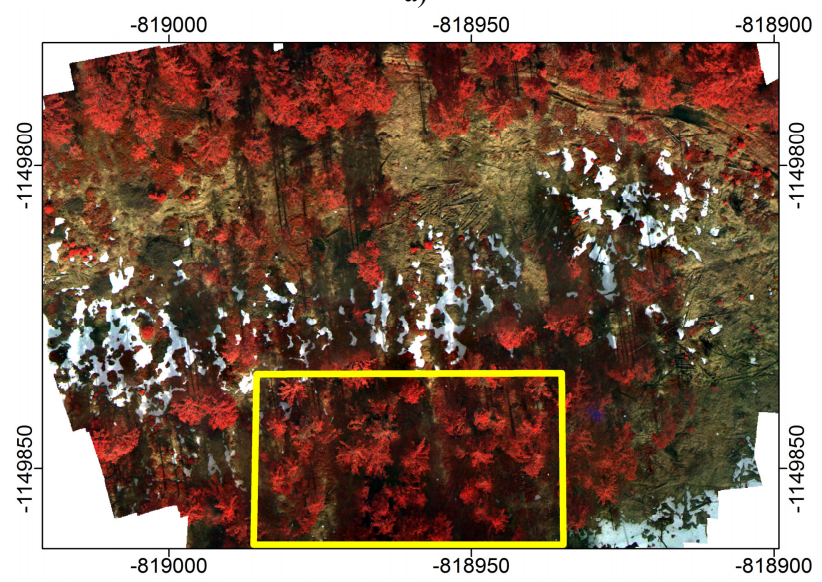

b)

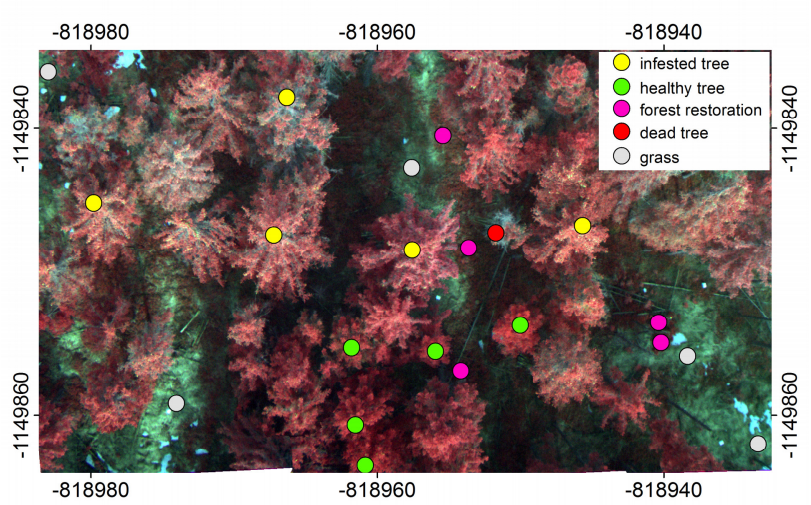

c)

Figure 1. Study area. a) Study region with marked Forest Infrared Index, b) Study site, where UAV imaging was performed, c) Research plot, analysed in this study. 


\subsection{UAV and Sensor}

In this study, we used a multi-rotor UAV, namely ARF MicroKopter OktoXL (Figure 2), developed by HiSystems $\mathrm{GmbH}$, Moormerland, Germany. The OktoXL was equipped by active gimbal with stabilised camera mount to balance the pitch and roll of the helicopter during the survey. The typical flight duration was around 15 minutes having the multispectral camera and two batteries on board.

To collect multispectral images we used Tetracam $\mu$-MCA Snap 6 , capturing imagery in six independent channels. Each channel is acquired by an independent camera with fixed lens, 1.3 megapixels $(1280 \times 1024$ pixels $)$ Complementary Metal Oxide Semiconductor (CMOS) global shutter sensor and changeable band pass filter. Global shutter sensor $\mu$-MCA Snap cameras was selected as preferred solution over the rolling shutter as it allows capturing imagery in conditions of faster and less stable UAV platforms (Tetracam, 2015). The key feature of the $\mu$ MCA array is a possibility to customize the composition of wavelength pass filters at each lens according to the needs of the research task.

The applied $\mu$-MCA Snap 6 array was equipped with a set of filters fitted to detection of vegetation stress resulting from the bark beetle infestation, covering also the red edge part of the spectrum. According to experimental laboratory study Masaitis et al. (2013), the red edge (701.0 - 715.7) is the most sensitive spectral zone for stress detection and for spectral separation between the needles taken from healthy Norway spruces and trees under stress. The data sets collected for this study had 550 , $650,700,800,850$ and $900 \mathrm{~nm}$ optical filters fitted, with a FullWidth at Half Maximum (FWHM) of $20 \mathrm{~nm}$.

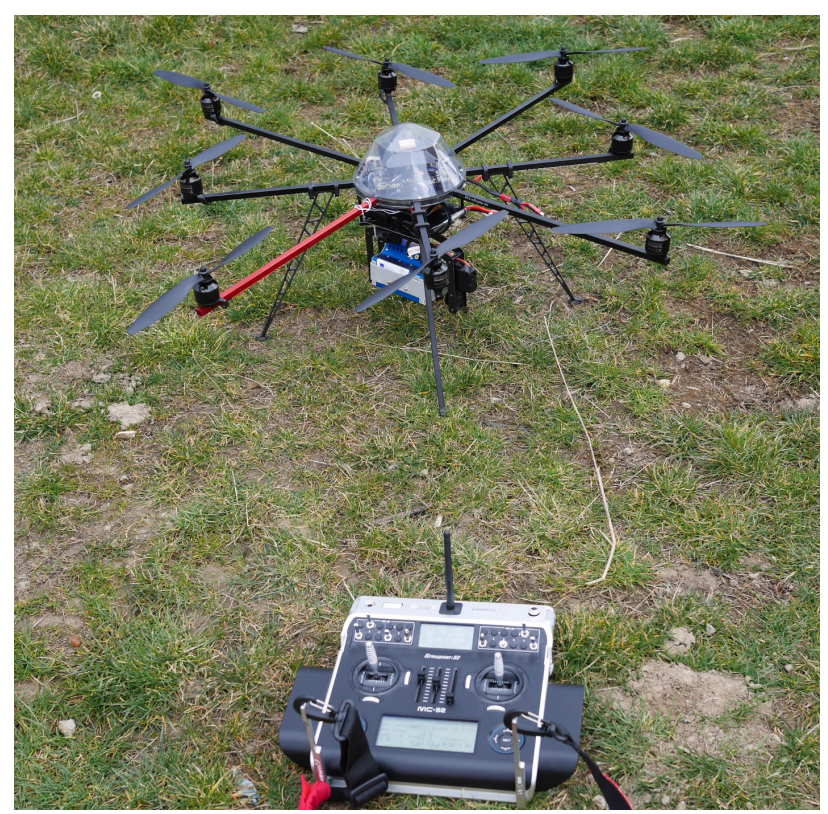

Figure 2. ARF MicroKopter Okto XL equipped with multispectral camera $\mu$-MCA

Snap 6.

\subsection{Data Acquisition}

Multispectral image acquisition was carried out on 4 April 2016 around 1 p.m. Weather condition were the windless and almost clear sky. The flight was proceded at an altitude of 50 meters covering a regular grid of $150 \times 100$ meters resulting in 200 multispectral images with the spatial resolution $2.5 \mathrm{~cm}$. Images were captured every second in continuous mode to keep at least $80 \%$ frontal and $60 \%$ side overlap. A reference calibration image of Teflon tag was captured directly before the flight. The main purpose was to compensate for ambient atmospheric and sun angle influences vs. reference standard conditions at the time of factory calibration (Tetracam, 2015).

Prior to survey flight, there were equally distributed white papers in A4 format, which acted as Ground Control Points (GCPs). The coordinates of 21 GCPs were measured by geodetic Global Navigation Satellite System (GNSS) receiver Topcon Hiper SR with achieved horizontal accuracy of $1.8 \mathrm{~cm}$ and vertical accuracy of $2.5 \mathrm{~cm}$.

\subsection{Photogrammetric Processing}

The Tetracam PixelWrench2 (PW2) was used for the raw images download via USB and data conversion to single page TIF file format which is readable for commonly used multispectral image analysis programs. The band-to-band registration step is automatically included in PW2 as part of the raw to multipage TIF format conversion based on camera's alignment file.

The photogrammetric processing was performed using Agisoft Photoscan Professional 1.2.4 developed by AgiSoft LLC, St. Petersburg, Russia. PhotoScan allows to perform the 3D reconstruction of the scene from the imagery, employing the Structure from Motion and Semi-Global Matching algorithms. The reliable performance of the software in the feature detection, image matching, and in consequent deriving of the dense point cloud, 3D model and ortho imagery has been proven in previous studies, e.g. Verhoeven (2011).

All of the 200 multispectral images, acquired in the imaging campaign over the study area were included into orientation processing. The band $4(800 \mathrm{~nm})$ was set as a master channel for estimating image orientations. After initial photo alignment, GCPs were used as markers to optimize the sparse cloud and to transform image orientation into geodetic coordinate system SJTSK Krovak East North (EPSG 5514). Seven GCPs served as checkpoints to evaluate the accuracy of alignment. The following steps in the workflow consisted in the dense cloud generation, automatic ground point classification. Based on these datasets, the Digital Terrain Model (DTM) and orthoimages were generated.

However, there is a limiting factor affecting the reliability of the data products, resulting from the photogrammetric workflow. In the Agisoft Photoscan, the orthoimage or even the single orthorectified images are resampled by the Bilinear Interpolation, which modifies the source Digital Number (DN) values of imagery. To avoid such modification and to retain the maximum possible reliability of the original $\mathrm{DN}$ values, the original images were used for qualitative analysis of the different categories of the forest disturbance and regeneration. The four selected original images were georeferenced in ArcGIS 10.3.1 using GCPs and distinctive terrain objects with Nearest Neighbourhood resampling method. Finally, the images were stitched ERDAS IMAGINE 2013. 


\subsection{Detection of forest disturbance}

The spectral response for given categories of forest damage status was analyzed across the multispectral bands. Based on the set of selected samples for each category, we have identified the typical DN values and their variation for each spectral band (Figure 3). One sample of a dead tree with a complete loss of canopy was added as an extra category into the analysis for better comparison of different disturbance phases. The analysis was performed within one image only to inhibit even subtle changes of DN caused by slightly different light conditions between images capturing. Each sample was represented by a circle containing approximately 525 pixels.

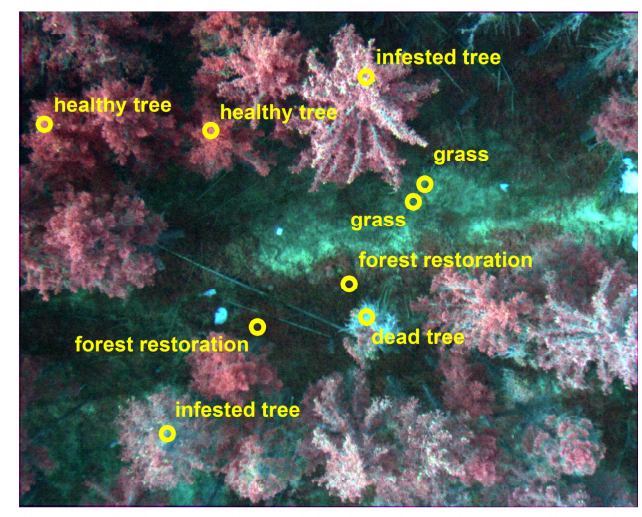

Figure 3. Selected appropriate samples for the spectral response analysis of different disturbance categories.

\begin{tabular}{|c|c|c|}
\hline Index & Formula & Reference \\
\hline Greenness Index & $\frac{\text { green }}{\text { red }}$ & $\begin{array}{l}\text { Le Maire et al. } \\
\qquad(2004)\end{array}$ \\
\hline $\begin{array}{l}\text { Simple ratio (SR) } \\
800 / 550\end{array}$ & $\frac{N I R}{\text { green }}$ & $\begin{array}{l}\text { Le Maire et al. } \\
\text { (2004) }\end{array}$ \\
\hline $\begin{array}{l}\text { Simple ratio } \\
800 / 650 \text { Pigment } \\
\text { specific SR B1 }\end{array}$ & $\frac{N I R}{r e d}$ & $\begin{array}{c}\text { Blackburn } \\
\text { (1998) }\end{array}$ \\
\hline Datt 2 & $\frac{N I R}{\text { red_edge }}$ & Datt (1999) \\
\hline NDVI & $\frac{N I R-\text { red }}{N I R+\text { red }}$ & Tucker (1979) \\
\hline Green NDVI & $\frac{N I R-\text { green }}{N I R+\text { green }}$ & $\begin{array}{c}\text { Gitelson and } \\
\text { Merzlyak (1997) }\end{array}$ \\
\hline $\begin{array}{l}\text { Red-edge index } \\
\text { (NDRE) }\end{array}$ & $\frac{N I R-(\text { red_edge })}{N I R+(\text { red_edge })}$ & $\begin{array}{l}\text { Barnes et al. } \\
\quad(2000)\end{array}$ \\
\hline $\begin{array}{l}\text { Red-edge Green } \\
\text { NDVI }\end{array}$ & $\frac{(\text { red_edge })-\text { green }}{(\text { red_edge })+\text { green }}$ & $\begin{array}{c}\text { Buschmann and } \\
\text { Nagel (1993) }\end{array}$ \\
\hline Red-edge NDVI & $\frac{(\text { red_edge })-r e d}{\left(r e d \_e d g e\right)+r e d}$ & $\begin{array}{l}\text { Ortiz et al. } \\
\text { (2013) }\end{array}$ \\
\hline $\begin{array}{l}\text { Anthocyanin } \\
\text { reflectance index } 2 \\
\text { (ARI2) }\end{array}$ & $\operatorname{NIR}\left[\left(\frac{1}{\text { green }}\right)-\left(\frac{1}{\text { red_edge }}\right)\right.$ & $\begin{array}{l}\text { Gitelson et al. } \\
\quad(2002)\end{array}$ \\
\hline
\end{tabular}

Table 1. Summary of selected vegetation indices used for tree stress detection caused by bark beetle infestation, where green is band $1(550 \mathrm{~nm})$, red is band $2(650 \mathrm{~nm})$, red_edge is band 3 $(700 \mathrm{~nm})$ and NIR is band $4(800 \mathrm{~nm})$.
The signal of the stress or vitality of vegetation in the context of remote sensing techniques is reflected by the changes in biochemical and biophysical characteristics of the trees. The bark beetle infestation correlates, among others, with the changes in the greenness and leaf pigments concentration (Lausch et al., 2013). Based on the previous works (Tuominen et al., 2009; Ortiz et al., 2013; Adamczyk and Osberger, 2015), suitable vegetation indices have been selected to detect tree stress with respect to the spectral sensibility of the camera (Table 1).

Based on the set of selected spectral indices (Table 1), there was performed analysis of their values at given categories of forest disturbance. The aim was to analyse the informative value of different spectral indices to detect the different qualitative stages of vegetation based on $\mu$-MCA Snap 6 sensor spectral bands. The assessed indicators are of three categories according to the principle of calculation - the simple ratio-like indices, the Normalized Difference Vegetation Indices (NDVI)-like indices and the Anthocyanin reflectance index 2 (ARI2).

Vegetation indices were extracted for all samples in every class within a buffer $25 \mathrm{~cm}$ around points. The number of samples was 5 for each class except dead trees category, in which was the only one (see Figure 1c). In the calculation process, the calibration values computed in PW2 were applied.

\section{RESULTS AND DISCUSSION}

\subsection{Photogrammetric processing}

The photogrammetric processing of multispectral images using Agisoft Photoscan resulted in a dataset with a re-projection error of 0.2 pixels. The root mean square error (RMSE) values of the seven checkpoints residuals were $0.07 \mathrm{~m}$ in horizontal (XY) plane and 0.14 in the $\mathrm{Z}$ direction. The resulting dataset represents the six-channel orthophoto with spatial resolution 2.5 $\mathrm{cm}$ (see Figure 1b). The photogrammetric processing accuracy is consistent with Turner et al. (2014) who state the accuracy of processing from 5.61 to $7.29 \mathrm{~cm}$ using former version (miniMCA) of the camera.

The only but great disadvantage is that Agisoft Photoscan supplies only Bilinear interpolation resampling method which modifies original DN values. This is not acceptable for the analysis of forest damage status and in general for every vegetation health analysis by means of remote sensing. For this reason, the alternative workflow similar to Lehman et al. (2015) using georeferenced images stitched in ERDAS IMAGINE was used (see Figure 1c). The selected original images were georeferenced according to orthophoto with an accuracy of approximately $20 \mathrm{~cm}$.

\subsection{Spectral response of different disturbance categories}

The spectral response analysis of different disturbance categories was performed (Figure 4). In comparison to the healthy trees, DN values of the infested trees are much higher in visible wavelengths and significantly lower in NIR wavelengths. Higher (radiance) DN values in the visible spectrum are an indicator of vegetation stress. The DN values of dead tree are separable only in the red and red-edge portion of the spectrum from infested trees. In the NIR wavelengths, there are no differences between DN values of dead and infested trees and also between categories forest restoration and grass. Results point to a greater sensitivity to variations of chlorophyll 
in the red and red-edge than in NIR part of the spectrum. The most informative bands for tree stress detection caused by bark beetle infestation are band $2(650 \mathrm{~nm})$ and band $3(700 \mathrm{~nm})$, followed by band $4(800 \mathrm{~nm})$ from the red-edge and NIR part of the spectrum. The spectral response analysis is consistent with previous works. The greater sensitivity of red-edge band for assessing vegetation stress has been confirmed in experimental studies of Datt (1998) and Le Maire et al. (2004).

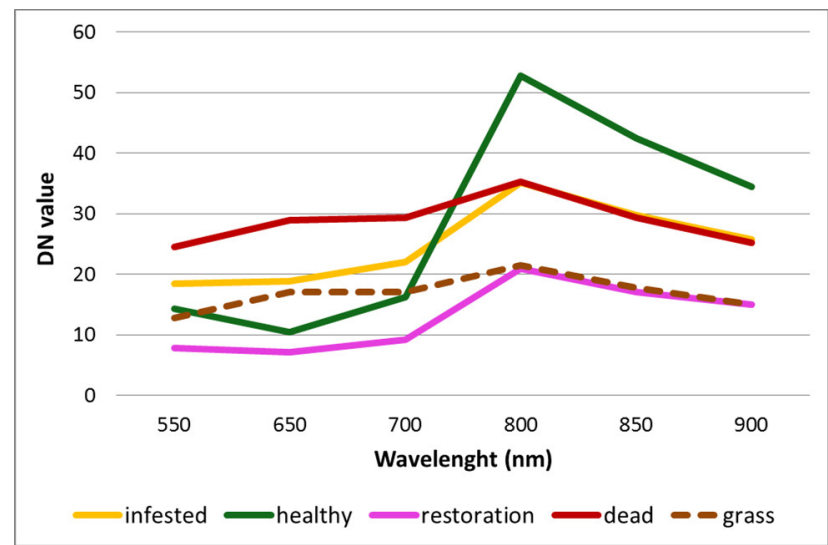

Figure 4. Average DN values of the established categories: infested trees, healthy trees, forest restoration, dead trees, and grass in the $550-900 \mathrm{~nm}$ spectral region.

\subsection{Vegetation indices}

The analysis of the variability of the values indicated the significant differences in sensitivity of the analysed indices to detect forest disturbance (Figure 5). Most of the assessed indicators are performing well in the detection of basic categories of a healthy forest, dead trees and the infested forest. These three categories are clearly separated while in particular the healthy forest and dead trees represent significantly unequivocal categories.

Most distinct separation of the basic categories with only marginal overlaps of values is apparent for Simple ratio 800/650 Pigment specific simple ratio B1 (Figure 5c), NDVI (Figure 5e) and the Red-edge index (Figure 5g). To the contrary, the fuzzy values even in these boundary categories are apparent in the Red-edge Green NDVI (Figure 5h) index and in the Anthocyanin reflectance index (Figure 5j), where the distinction of categories is almost impossible.

The key differences among the indices performance are apparent in their ability to distinguish the transition categories. In particular, it applies to the categories of the regenerating vegetation from the grass and infested trees. The distinction of the heterogeneous categories appeared to be complicated for most of the indicators. Despite the correct distinction at the level of mean values, the most common problem is the variability of values, resulting in significant overlaps.

We have identified only three indices, which seems to be able to correctly detect different forest disturbance categories in the complex conditions of a mixture of categories. From the tested indices, the best ability to separate the different categories was apparent in the classic NDVI index (Figure 5e). Among the analysed indices this was the only index where the interquartile range of values (IRQ) was without overlaps among the given categories. The Simple ratio $800 / 650$ index (Figure 5c) is then able to distinctly separate the high forest from the understory vegetation and fair distinction between the infested and the regenerating forest categories. As the third well performing index, we can identify the Red-edge index (Figure $5 \mathrm{~g}$ ), which offers very narrow bands of IRQ variability suggesting good separability with only marginal overlaps among the categories. This confirms the statements by Datt (1999) and observations by Gitelson et al. (2006) concerning the use of red-edge and NIR reflectance as an indicator of forest health.

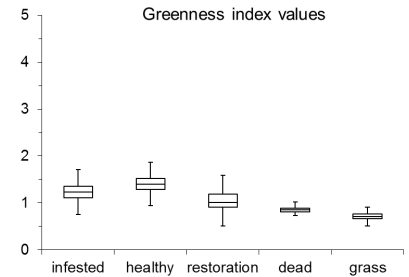

a)

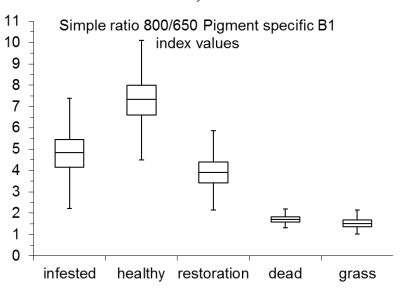

c)

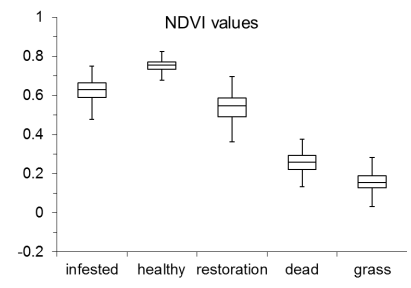

e)

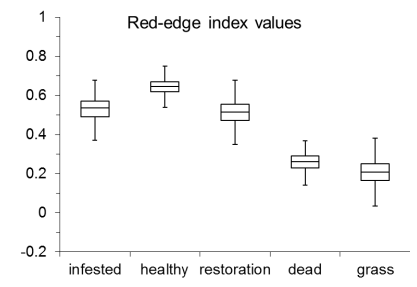

g)

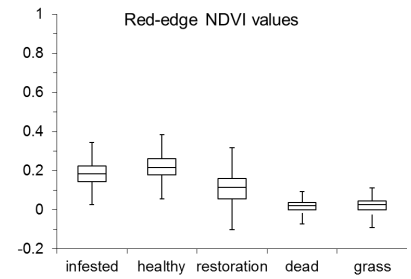

i)

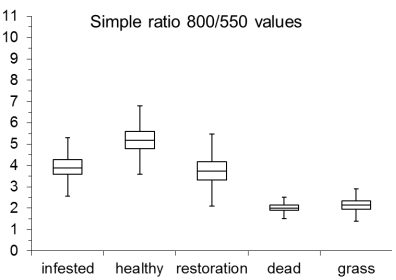

b)

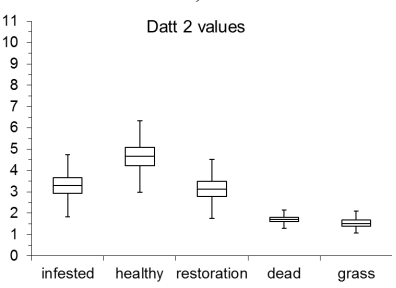

d)

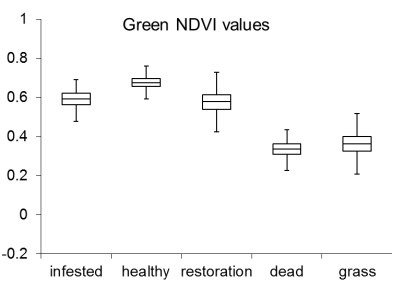

f)

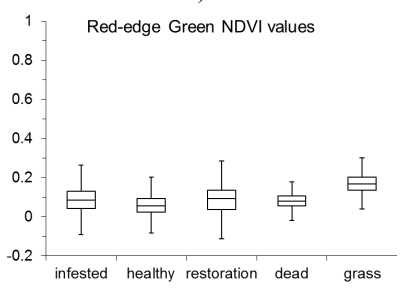

h)

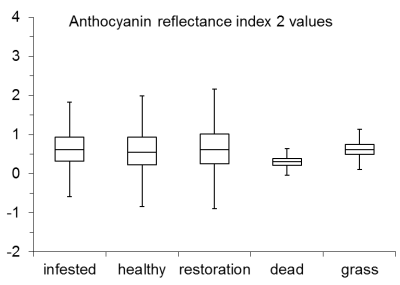

j)

Figure 5. Distribution of values of the selected vegetation indices in tested categories of forest disturbance.

The differences in calculation among the three indices are apparent after their application to the study area (Figure 6). Every index has differently shaped histogram, tending in the case of NDVI to higher values (Figure 6a), for the NDRE to 
mid-values (Figure 6b) and in the case of SR 800/650 index to the low values (Figure 6c). The diverging shape of histograms implies the different sensitivity of the three indices, calculated based on the $\mu$-MCA Snap 6 data to the different stages of forest disturbance.

Histogram of the NDVI index is left-skewed towards the higher NDVI values. Such distribution suggests a better sensitivity of the index to healthy, regenerating and slightly disturbed forest cover. The distribution of NDRE index is most symmetric from the three indices with the slight left-skewed shape of the histogram, similar to the NDVI index. The NDRE index thus appears as most balanced, however, with potential overlaps in the zone of low values, i.e. the areas of damaged or low vegetation. To the contrary, the Simple ration 800/650 features a right-skewed distribution where the substantial part of the index values variability is covering the lower values. It suggests suitability for better separation of the categories with less dense canopy, open areas, heavily disturbed or dead trees.

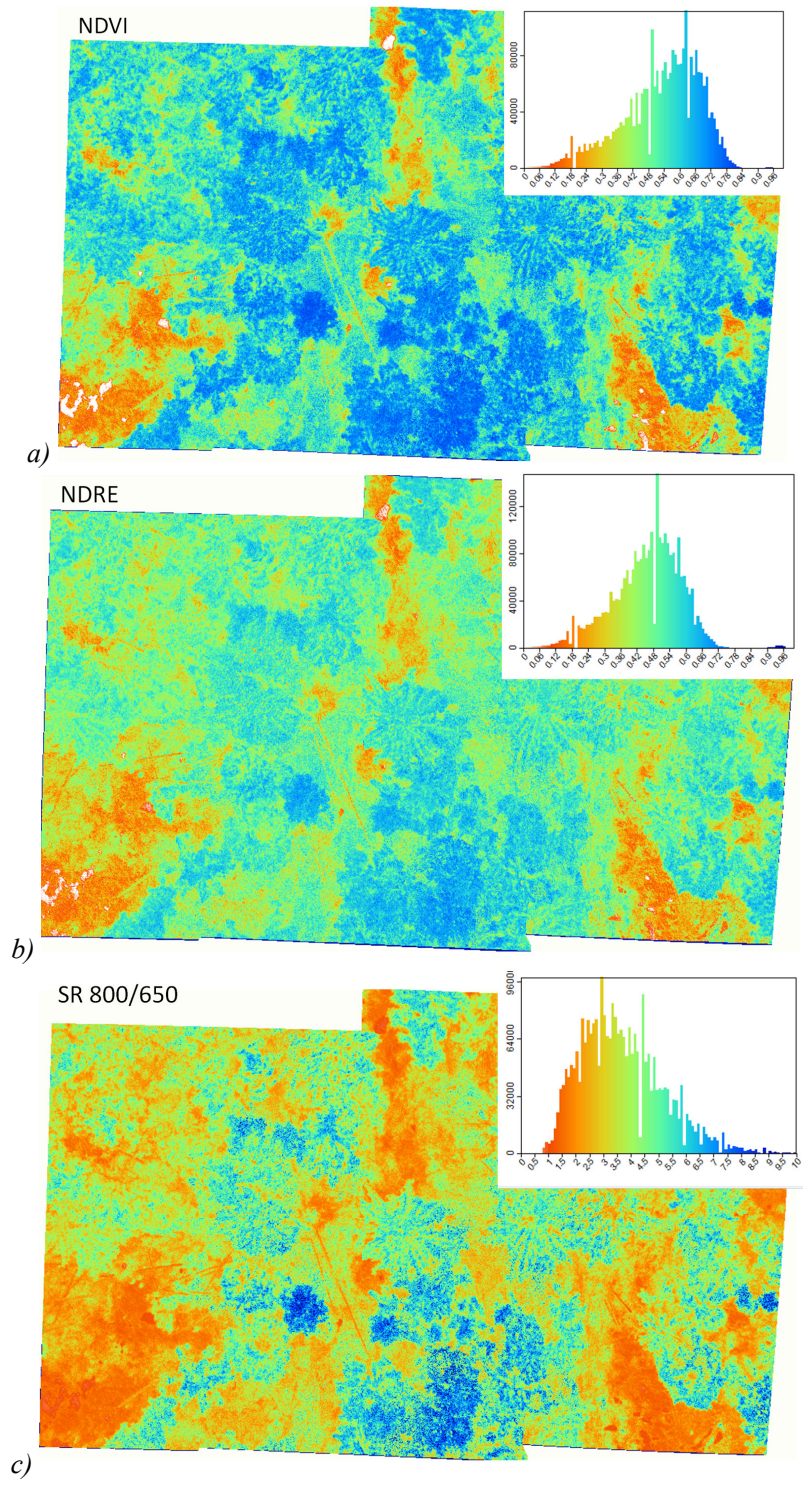

Figure 6. Spatial distribution of NDVI (a), SR 800/650 (b) and NDRE (c) indices over the study site.

\section{CONCLUSIONS}

In this paper, there are presented first results of the research study, aimed to employ the potential of the ultra-high resolution multispectral imagery for analysis of the signal of forest disturbance and regeneration in the montane spruce forest. The research was focused on a study site featuring the key stages of forest health status occurring in the area, including the healthy, disturbed and dead trees, the open areas, and newly regenerating vegetation.

The multirotor UAV equipped with the multispectral camera $\mu$ MCA Snap 6 was first applied to test the applicability of the sensor for such analysis on the example of mid-latitude forest, attacked by the extensive bark beetle infestation. The spectral bands of the $\mu$-MCA Snap 6 sensor were set to cover the reflectance in green, red, red edge and near infrared zone (550, $650,700,800,850$ and $900 \mathrm{~nm}$ ) with a relatively narrow band width $(20 \mathrm{~nm})$. Based on the acquired imagery there was calculated a set of spectral indexes, applied in forest disturbance studies.

For the given indexes and there was tested the distribution of values in the test sites, reflecting the samples of the key categories of the forest status. Most of the tested indexes were able to correctly distinguish the boundary categories represented by the healthy and dead trees. The Anthocyanin reflectance index or Red-edge GNDVI were only two indexes unable to separate even such distinct categories of forest status and thus were excluded from the further analyses of the forest disturbance with the given data. The testing, however, proved that the distinct separation is difficult for the categories reflecting the transition of the status or featuring a mixture of categories like the slightly or heavily infested trees or the regenerating forest. There were identified only three indexes NDVI, SR 800/650 Pigment Specific simple ratio B1 and NDRE, where the selected categories forest status are reflected by crisp ranges of values with distributions, not overlapping with the other categories.

For these best performing indicators there was tested the distribution of values their spatial variability and sensitivity to detect different stages of forest disturbance. Although all of the indexes are able to distinguish event the subtle differences in the forest status, they have varyingly skewed distributions of values, resulting in diverse sensitivity to the different stages of forest disturbance. Thus, the NDVI index has higher variability in the zone of the healthy or slightly disturbed forest. In contrast, the SR $800 / 650$ has higher sensitivity in the zone of the disturbed forest cover.

The study proved the good applicability of coupling the UAV imaging with multispectral sensors for analysis of the forest disturbance. The ultra-high resolution of imagery in combination with the high operability of UAV imaging is enabling to study the spatial distribution of the forest disturbance in different qualitative stages and dynamics in space and time. However, as the resolution at the level of centimetres allows distinguishing individual tree branches or trunks, it brings also new challenges for interpretation and analysis, based on the uneasy treatment of transient or mixed categories.

The narrow bands of the multispectral sensor allow using the indexes, sensitive to the area of values according to the needs of the task. As the $\mu$-MCA sensor allows working with used defined spectral bands, the further challenge is in also in the 
testing of configurations of the spectral bands, in particular in the red-edge and near-infrared zone, which might result in more accurate detection of the signal of forest disturbance.

\section{ACKNOWLEDGEMENTS}

The research was supported by the EU COST Action 1306 project LD15130 "Impact of landscape disturbance on the stream and basin connectivity".

The authors would like to thank Theodora Lendzioch for her kind help with collecting the UAV imagery and support.

\section{REFERENCES}

Adamczyk, J. and Osberger, A., 2015. Red-edge vegetation indices for detecting and assessing disturbances in Norway spruce dominated mountain forests. International Journal of Applied Earth Observation and Geoinformation, 37, pp. 90-99.

Barnes, E. M., Clarke, T. R., Richards, S. E., Colaizzi, P. D., Haberland, J., Kostrzewski, M., Waller, P., Choi, C. and Lascano, R. J., 2000. Coincident detection of crop water stress, nitrogen status and canopy density using ground based multispectral data. In: Proceedings of the 5th International Conference on Precision Agriculture, Bloomington, MN, July, pp. 16-19.

Berni, J. A., Zarco-Tejada, P. J., Suárez, L. and Fereres, E., 2009. Thermal and narrowband multispectral remote sensing for vegetation monitoring from an unmanned aerial vehicle. Geoscience and Remote Sensing, IEEE Transactions on, 47(3), pp. 722-738.

Blackburn, G. A., 1998. Quantifying chlorophylls and caroteniods at leaf and canopy scales: An evaluation of some hyperspectral approaches. Remote sensing of environment, 66(3), pp. 273-285.

Borrelli, P., Panagos, P., Langhammer, J., Apostol, B. and Schütt, B., 2016. Assessment of the cover changes and the soil loss potential in European forestland: First approach to derive indicators to capture the ecological impacts on soil-related forest ecosystems. Ecological Indicators, 60, pp. 1208-1220.

Buschmann, C. and Nagel, E., 1993. In vivo spectroscopy and internal optics of leaves as basis for remote sensing of vegetation. International Journal of Remote Sensing, 14(4), pp. 711-722.

Campbell, P. E., Rock, B. N., Martin, M. E., Neefus, C. D., Irons, J. R., Middleton, E. M. and Albrechtova, J., 2004. Detection of initial damage in Norway spruce canopies using hyperspectral airborne data. International Journal of Remote Sensing, 25(24), pp. 5557-5584.

Chambers, J. Q., Asner, G. P., Morton, D. C., Anderson, L. O., Saatchi, S. S., Espírito-Santo, F. D., Palace, M. and Souza, C., 2007. Regional ecosystem structure and function: ecological insights from remote sensing of tropical forests. Trends in Ecology \& Evolution, 22(8), pp. 414-423.

Datt, B., 1998. Remote sensing of chlorophyll a, chlorophyll b, chlorophyll $\mathrm{a}+\mathrm{b}$, and total carotenoid content in eucalyptus leaves. Remote Sensing of Environment, 66(2), pp. 111-121.
Datt, B., 1999. Visible/near infrared reflectance and chlorophyll content in Eucalyptus leaves. International Journal of Remote Sensing, 20(14), pp. 2741-2759.

Frelich, L. E., 2002. Forest dynamics and disturbance regimes, studies from temperate evergreen-deciduous forests. Cambridge University Press, Cambridge, UK.

Gitelson, A. A. and Merzlyak, M. N., 1997. Remote estimation of chlorophyll content in higher plant leaves. International Journal of Remote Sensing, 18(12), pp. 2691-2697.

Gitelson, A. A., Zur, Y., Chivkunova, O. B. and Merzlyak, M. N., 2002. Assessing carotenoid content in plant leaves with reflectance spectroscopy. Photochemistry and Photobiology, 75(3), pp. 272-281.

Gitelson, A. A., Keydan, G. P. and Merzlyak, M. N., 2006. Three-band model for noninvasive estimation of chlorophyll, carotenoids, and anthocyanin contents in higher plant leaves. Geophysical research letters, 33(11), pp. 1-5.

Göthlin, E., Schroeder, L. M. and Lindelöw, A., 2000. Attacks by Ips typographus and Pityogenes chalcographus on windthrown spruces (Picea abies) during the two years following a storm felling. Scandinavian Journal of Forest Research, 15(5), pp. 542-549.

Hais, M., Jonášová, M., Langhammer, J. and Kučera, T., 2009. Comparison of two types of forest disturbance using multitemporal Landsat TM/ETM+ imagery and field vegetation data. Remote Sensing of Environment, 113(4), pp. 835-845.

Heurich, M., Ochs, T., Andresen, T. and Schneider, T., 2010. Object-orientated image analysis for the semi-automatic detection of dead trees following a spruce bark beetle (Ips typographus) outbreak. European Journal of Forest Research, 129(3), pp. 313-324.

Kulakowski, D. and Bebi, P., 2004. Range of Variability of unmanaged subalpine forests. In: Conference proceedings: Forum für Wissen: Schutzwald und Naturgefahren, Davos, Switzerland. October 28-29, pp. 47-54.

Laliberte, A. S., Goforth, M. A., Steele, C. M. and Rango, A., 2011. Multispectral remote sensing from unmanned aircraft: Image processing workflows and applications for rangeland environments. Remote Sensing, 3(11), pp. 2529-2551.

Langhammer, J., Su, Y. and Bernsteinová, J., 2015. Runoff Response to Climate Warming and Forest Disturbance in a Mid-Mountain Basin. Water, 7(7), pp. 3320-3342.

Latifi, H., Schumann, B., Kautz, M. and Dech, S., 2014. Spatial characterization of bark beetle infestations by a multidate synergy of SPOT and Landsat imagery. Environmental monitoring and assessment, 186(1), pp. 441-456.

Lausch, A., Heurich, M., Gordalla, D., Dobner, H. J., GwillymMargianto, S. and Salbach, C., 2013. Forecasting potential bark beetle outbreaks based on spruce forest vitality using hyperspectral remote-sensing techniques at different scales. Forest Ecology and Management, 308, pp. 76-89. 
Lehmann, J. R. K., Nieberding, F., Prinz, T. and Knoth, C., 2015. Analysis of unmanned aerial system-based CIR images in forestry-A new perspective to monitor pest infestation levels. Forests, 6(3), pp. 594-612.

Le Maire, G., Francois, C. and Dufrene, E., 2004. Towards universal broad leaf chlorophyll indices using PROSPECT simulated database and hyperspectral reflectance measurements. Remote sensing of environment, 89(1), pp. 1-28.

Lindner, M., Maroschek, M., Netherer, S., Kremer, A., Barbati, A., Garcia-Gonzalo, J., Seidl, R., Delzon, S., Corona, P., Kolström, M., Lexer, M. J. and Marchetti, M., 2010. Climate change impacts, adaptive capacity, and vulnerability of European forest ecosystems. Forest Ecology and Management, 259(4), pp. 698-709.

Masaitis, G., Mozgeris, G. and Augustaitis, A., 2013. Spectral reflectance properties of healthy and stressed coniferous trees. Iforest-biogeosciences and Forestry, 6(1), pp. 30-36.

Näsi, R., Honkavaara, E., Lyytikäinen-Saarenmaa, P., Blomqvist, M., Litkey, P., Hakala, T., Viljen, N., Kantola, T., Tanhuanpää, T. and Holopainen, M., 2015. Using UAV-Based Photogrammetry and Hyperspectral Imaging for Mapping Bark Beetle Damage at Tree-Level. Remote Sensing, 7(11), pp. 15467-15493.

Ortiz, S. M., Breidenbach, J. and Kändler, G., 2013. Early detection of bark beetle green attack using TerraSAR-X and RapidEye data. Remote Sensing, 5(4), pp. 1912-1931.

Salamí, E., Barrado, C. and Pastor, E., 2014. UAV flight experiments applied to the remote sensing of vegetated areas. Remote Sensing, 6(11), pp. 11051-11081.

Tetracam, 2015. Tetracam $\mu$-MCA User's Guide, Tetracam Inc., Los Angeles, CA, USA.

Topcon, 2012. HiPer SR Operator's manual, Topcon Positioning Systems, Inc., Livermore, CA, USA.

Tucker, C. J., 1979. Red and photographic infrared linear combinations for monitoring vegetation. Remote sensing of Environment, 8(2), pp. 127-150.

Tuominen, J., Lipping, T., Kuosmanen, V., and Haapanen, R., 2009. Remote sensing of forest health. In: Geoscience and Remote Sensing, InTech, Rijeka, Croatia, pp. 29-52.

Turner, D., Lucieer, A. and Watson, C., 2011. Development of an Unmanned Aerial Vehicle (UAV) for hyper resolution vineyard mapping based on visible, multispectral, and thermal imagery. In: Proceedings of 34th International Symposium on Remote Sensing of Environment, Sydney, NSW, Australia, 10 15 April, pp. 1-4.

Turner, D., Lucieer, A., Malenovský, Z., King, D. H., and Robinson, S. A., 2014. Spatial co-registration of ultra-high resolution visible, multispectral and thermal images acquired with a micro-UAV over Antarctic Moss Beds. Remote Sensing, 6(5), pp. 4003-4024.
Verhoeven, G., 2011. Taking computer vision aloftarchaeological three-dimensional reconstructions from aerial photographs with photoscan. Archaeological Prospection, 18(1), pp. 67-73.

Zhang, C. and Kovacs, J. M., 2012. The application of small unmanned aerial systems for precision agriculture: a review. Precision agriculture, 13(6), pp. 693-712. 